\title{
Forecasting of Badr Airlines Domestic Services Total Cost
}

\author{
Maysoon A. Sultan ${ }^{* 1}$, Mohammed H. Mudawi ${ }^{2}$ and Afra H. Abdellatif ${ }^{3}$ \\ ${ }^{1 .}$ Department of Statistics, Faculty of Science, Sudan University for Sciences and Technology, Khartoum, Sudan. \\ ${ }^{2}$ Department of Statistics, Faculty of Science, Juba University, Juba, South Sudan. \\ ${ }^{3}$ Department of Statistics, Faculty of Science, Sudan University for Sciences and Technology, Khartoum, Sudan.
}

\begin{abstract}
This paper attempt to estimate and forecast the total cost of Badr Airlines domestic services. The data were obtained from the Planning Directorate of Sudan Civil Aviation Authority and Air Transport Directorate. The data were statistically analyzed the annual cost function of Badr Airlines for the period from 2004 to 2013. The researcher study was to find out how the total cost (TC) behaves in relation to the domestic output, in revenue passenger (PAX), cargo/ freight (FRT), fuel cost (FC) and load factor (LF). The result shall lead us to estimate an airline cost function, by using Classical Normal Regression model (CNLRM) to analyze the data obtained for this research. The model is represented as follows:

$T C_{t}=\beta_{0}+\beta_{1} P A X_{t}+\beta_{2} F R T_{t}+\beta_{3} L F_{t}+\beta_{4} F C_{t}+u_{t}$

$t=1,2, \ldots, 10$

The Classical Normal Linear Regression Model (CNLRM) is acceptable to the predictive purpose of forecasting the function of Badr Airlines total cost, with a high statistically significant value at $5 \%$ level. This result means that the estimated regression models make sense; with strong power for prediction and forecast. From the forecast result for the period 2014-2018 the researcher concluded that the total cost of Badr Airlines, shall increase during the next five years. This is clearly noted in Badr Airlines activities as reflected in their current actual status in 2016, due to its remarkable increasing fleet number and operational activities and route.
\end{abstract}

Keywords: Classical Linear Regression Model, Passenger, Freight, Fuel Price, Load Factor.

\section{Introduction}

The company was founded as Sarit Air Lines in 1997 and was renamed in 2004, due to numerous fatal air crashes, when the Antonov 12 was carrying food and money on a routing flight from Khartoum, and after obtaining permission to land, it exploded in the air about $6 \mathrm{~km}$ from Wau Air port (2003), in which proceeding investigations showed that the airline disregarded many CAA [clarification needed] safety regulations, including but not limited, to overloading of the aircraft and bribing of its air crew to overlook overloading of the aircraft !. (S.C.A.A., 2012).

Badr Air lines fleet consist of the following aircraft:

Table (1): Badr Air Active Fleet:

\begin{tabular}{|r|r|}
\hline Aircraft & In Fleet \\
\hline Boeing 737-300 & 2 \\
\hline Boeing 737-500 & 2 \\
\hline Ilyushin IL-76 TD & 2 \\
\hline Antonov AN-26B-100 & 1 \\
\hline Antonov AN-74 T 200 & 1 \\
\hline Antonov AN-74 TK-100 & 1 \\
\hline Antonov 2 & 1 \\
\hline Antonov 28 & 1 \\
\hline Total & $\mathbf{1 1}$ \\
\hline
\end{tabular}

Source: S.C.A.A. Sudan Civil Aviation Integrated Statistics, (2012).

In this paper ten years annual data of total domestic passengers and cargo, from 2004 to 2013, are statistically analyzed to determine a cost function.

Research Problem:

Preface:

1. Covers all States of Sudan.

2. Badr Airlines Domestic movements carrying passengers and cargo during 2004- 2013.

The research objectives are list below:

1. Evaluation of Badr Airlines domestic Services in Sudan in regards to Passenger / Cargo Movements.

2. Statistical Estimation \& Forecast of a Badr Airlines cost function to identify the extent of aviation development in Sudan. 


\section{Materials \& Methods}

Cost models are mathematical representation of the relationship between the total cost and explanatory variables (the output, in revenue passenger and cargo, fuel price and load factor), model specification reflects expectations of cost behavior, by using the Classical Normal Linear Regression Model (CNLRM), to evaluate the model for forecasting, by satisfying the main features of a good regression model.

\section{Theoretical Frame:}

Analysis of the data obtained from the Planning Directorate of Sudan Civil Aviation Authority and Air Transport Directorate. These data consist of the total number of passengers and freight/cargo carried domestically in Badr Airlines, and also the data consist of the total number and types of aircraft in Badr Airlines through the years from 2004 to 2013. Addition of that the data of Fuel price obtained from Nile Bakri Aviation Co.Ltd., and price of currency from Bank of Sudan; which were used in calculation of Badr Airlines total cost.

\section{Specifications and Estimation of the Models:}

- The data analyze the annually cost of Badr Airlines for the period from 2004 to 2013.

- The researcher interested in finding out how the total cost (TC) behaves in relation to the domestic output, in revenue passenger (PAX) and cargo/ freight (FRT), fuel cost (FC) and load factor (LF). The result shall lead us to estimate Sudan Airways cost function, by using Classical Normal Linear Regression Model (CNLRM), and evaluate the model for forecasting. The model represented as follow:

$T C_{t}=\beta_{0}+\beta_{1} P A X_{t}+\beta_{2} F R T_{t}+\beta_{3} L F_{t}+\beta_{4} F C_{t}+u_{t} \quad, \quad t=1, \ldots, 10(1)$

And satisfied the main features of a good regression model ${ }^{(3),(4),(5),(6)}$, represented by:

Feature (1): Regression line must be fitted to data strongly. Value of R-square should be more than $60 \%$, because the higher R-square value; better the model or model fitted.

Feature (2): Most of explanatory variables (at least 50\%) should individually significant to explain dependent variable. Here t-test was performed.

Feature (3): Explanatory variables should be jointly significant to explain dependent variables. Here F-test should be performed.

Feature (4): Residuals of the model have no serial correlation, no heteroscedasticity and are normally distributed.

- By using the Simple Exponential Smoothing (smoothing parameter equals 0.7), the researcher forecasted the data of the explanatory variables, and then used the results to forecast Sudan Airways total cost from 2014 to 2018 , by using CNLRM.

- CNLRM shall be applied by using the Eview Statistical Package to estimate an airline cost function.

Evaluation of the Model: ${ }^{(7)}$

\section{Results \& Discussion}

The estimated value of total cost by using (CNLRM) is represented as follows:

Table (2): Significant Value of the Total cost (TC) regression Model (2) of Badr Airlines:

\begin{tabular}{|l|l|l|}
\hline Variable & Coefficient & Prob. \\
\hline C & 5667100 & 0.0000 \\
\hline PAX & 53.89931 & 0.0226 \\
\hline FRT & -0.063447 & 0.6302 \\
\hline LF & -8774699 & 0.002 \\
\hline FC & 1.085344 & 0.0000 \\
\hline
\end{tabular}

Source: Prepared by the researcher.

$T C_{t}=5667100+53.89931 \mathrm{PAX}_{\mathrm{t}}-0.063447 \mathrm{FRT}_{\mathrm{t}}-8774699 \mathrm{LF}_{\mathrm{t}}+1.085344 F C_{t}$

As shown in the table (2), there is $75 \%$ of the explanatory variables: passengers (PAX), load factor (LF) and fuel cost (FC); are statistically significant at level 5\%, to influence the dependent variable; total cost (TC).

Table (3): Tests Results of Goodness of Fit of the Estimated Regression Model (2):

\begin{tabular}{|l|l|}
\hline R-squared & 0.995109 \\
\hline Prob(F-statistic) & 0.000006 \\
\hline Durbin-Watson stat. & 1.976693 \\
\hline Jarque-Bera-Normality Prob. & $\mathbf{0 . 5 1 0 2 0 3}$ \\
\hline Breusch-Godfrey Serial Correlation Chi-square Prob. & 0.4906 \\
\hline Breusch-Pagan-Godfrey Heteroscedasticity Chi-square Prob. & $\mathbf{0 . 4 4 0 6}$ \\
\hline
\end{tabular}

Source: Prepared by the researcher. 
The R-squared value of about 0.995109 is statistically significant value (more than $60 \%$ ), means that about $99.5 \%$ of variation in the total cost is explained by passenger, freight, load factor and fuel cost; that means the goodness of fit of the regression line is very high. Durbin-Watson statistic (1.976693) is found to be 2, so there is no first-order autocorrelation, either positive or negative. Also the R-squared (0.995109) is less than Durbin-Watson statistic, which means this model is not spurious. The probability of F-statistic equal to 0.000006 is statistically significant at level $5 \%$, means that the independent variables: passenger, freight, load factor and fuel cost are jointly significant to influence the total cost.

The P-value of Jarque-Bera normality test equal to 0.510203 is not statistically significant value at $5 \%$ level; so, we cannot reject the null hypothesis; that residuals are normally distributed.The R-squared P-value of Breusch-Godfrey serial correlation LM test equal to 0.4906 is not statistically significant at $5 \%$ level; so, we cannot reject the null hypothesis; that residuals are not serial correlation. The R-squared P-value of BreuschPagan-Godfrey heteroscedasticity test equal to 0.4406 is not statistically significant value at $5 \%$ level; so, we cannot reject the null hypothesis; that residuals are not heteroscedasticity.

According to the above results, the researcher concludes that the residuals are normally distributed, not autocorrelated and homoscedastic; so, this result means that the estimated regression makes sense and is acceptable to predictive purposes and forecasting.

Forecasting:

Table (4): Result of Forecasting Sample 2004-2013 of Badr Airlines:

\begin{tabular}{|l|l|}
\hline Root Mean Squared Error & $\mathbf{4 1 8 7 9 4 . 4}$ \\
\hline Theil Inequality Coefficient & $\mathbf{0 . 0 1 7 1 4 5}$ \\
\hline Bias Proportion & $\mathbf{0 . 0 0 0 0 0}$ \\
\hline
\end{tabular}

Source: Prepared by the researcher.

As shown in table (4), the root mean squared error is equal to 418794.4 , while Theil Ineqauality coefficient equal to 0.017145 , which is close to zero, that means, the predictive power of this model is very strong. Bias proportion is equal to zero, that means, there is no gap between the actual total cost and the predictive total cost, and they are moving closely.

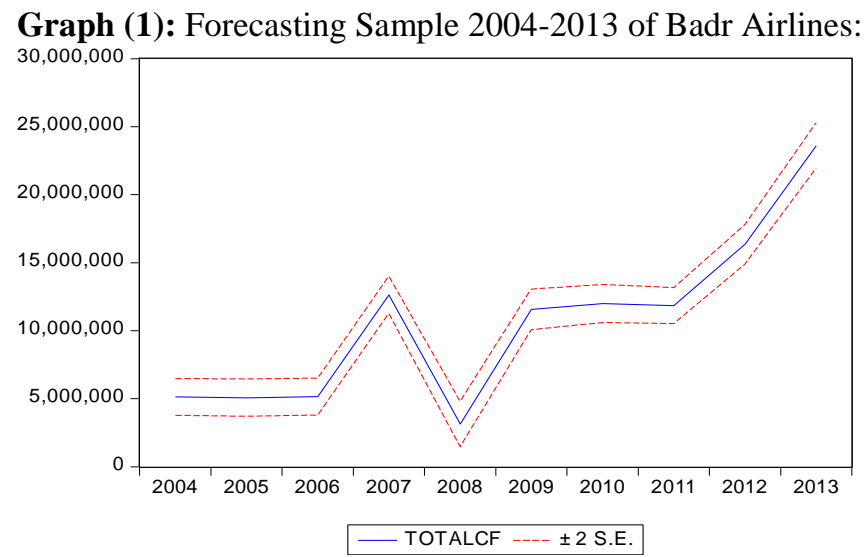

Source: Prepared by the researcher.

As shown in graph (1), the total cost value has been forecast and is passing throw $50 \%$ confidence interval; so, the forecasting of the total cost is significant and the ability of forecasting model is satisfactory.

\section{Forecasting of Badr Airlines Total Cost:}

By using the Simple Exponential Smoothing (smoothing parameter equals 0.7), the researcher forecasted the data of the explanatory variables, and then used the results to forecast Sudan Airways total cost from 2014 to 2018, by using CNLRM which is represented in the following table:

Table (5): Forecasting of Badr Airlines Total Cost (US \$) From 2014-2018:

\begin{tabular}{|l|l|l|l|l|l|}
\hline Year & 2014 & 2015 & 2016 & 2017 & $\mathbf{2 0 1 8}$ \\
\hline Total Cost & $\mathbf{3 4 5 7 1 5 1 . 6 7}$ & $\mathbf{5 0 0 4 1 1 5 . 5 0}$ & $\mathbf{5 4 6 8 2 0 4 . 6 5}$ & $\mathbf{5 6 0 7 4 3 1 . 4 0}$ & $\mathbf{5 6 4 9 1 9 9 . 4 2}$ \\
\hline \multicolumn{5}{|c|}{ Source: Prepared by the researcher. }
\end{tabular}

The forecast table above (5), shows that the total cost of Badr Airlines, shall increase during the next five years. This is clearly noted in Badr Airlines activities as reflected in their current actual status in 2016, due to its remarkable increasing fleet number and operational activities and route. 
To recapitulate, the following conclusions are detailed here below:

- The Classical Normal Linear Regression Model (CNLRM) is acceptable to the predictive purpose of forecasting the function of Badr Airlines total cost, with a high statistically significant value of R-squared (99\%), and statistically significant value of F-statistic at level 5\%. Additionally, the residuals were Normally distributed; P-value of Jarque-Bera Normality Test is not statistically significant value at 5\% level, and also the residuals were not autocorrelation (not serial correlation); P-value of Breusch-Godfrey Serial Correlation; LM Test is not statistically significant value at $5 \%$ level, also the residuals were homoscedastic; R-squared P-value of Breusch-Pagan-Godfrey Heteroscedasticity Test; is not statistically significant value at $5 \%$ level. The Theil Ineqauality coefficients values are close to zero and zero Bias Proportions. These results mean that the estimated regression models make sense; with strong power for prediction and forecast.

- From the forecast result for the period 2014-2018 the researcher concluded that the total cost of of Badr Airlines shall increase during the next five years. This is clearly noted in Badr Airlines activities as reflected in their current actual status in 2016, due to its remarkable increasing fleet number and operational activities and route.

\section{References}

[1]. S.C.A.A. (2012). Sudan Civil Aviation Integrated Statistics Centre, Khartoum, Sudan.

[2]. C.A.A., (2012). Sudan Civil Aviation Planning Directorate, Khartoum, Sudan.

[3]. Gujarati, D.N. and Porter, D.C. (2009). Basic Econometrics, Fifth Edition, Uni McGraw-Hill Companies.ted State Military Academy,West Point and University of Southern California.

[4]. Maddala, G.S. (1992). Introduction to Econometrics, Second Edition. University of Florida, Macmillan Publishing Company.

[5]. Greene, W.H. (1951). Econometric Analysis, Fifth Edition. New York University, Upper Saddle River, New Jersey.

[6]. Rawlings, J.O., Pantula, S.G. and Dickey D.A. (1932). Applied Regression Analysis: A Research Tool, Second Edition. North Carolina State University, Springer, USA.

[7]. Sultan, M.A., Mudawi, M.H. and Abdellatif, A.H. (2016). Past, Present \& Future of Airlines Domestic Services in Sudan. IOSR Journal of Mathematics (IOSR-JM).12(3), Ver. IV, 74-85. 